\title{
An ergonomic study on the onset of mental fatigue among the load handling workers of a central market area in Kolkata
}

\author{
Somnath Gangopadhyay and Tamal Das \\ Occupational Ergonomics Laboratory, Department of Physiology, University College of Science and Technology, \\ University of Calcutta, 92, APC Road, Kolkata-700 009, India
}

\begin{abstract}
It is a well recognized fact that manual material handling (MMH) entails enormous physical labor and associated discomfort feeling, which invariably culminate into musculoskeletal disorders. However mental fatigue, in such instances, becomes an unexplored parameter that needs definite attention during assessment of work status of MMH workers. The present study is being performed among 75 porters of a central market in Kolkata to ascertain the extent of physical and mental exhaustion among them. SF-12 health status questionnaire followed by another questionnaire involving psychosocial questions were performed among them. The analysis of both the questionnaires clearly revealed that most of the porters are under severe physical exertion as they alone carry about $120 \mathrm{~kg}$ load at a time and such activity is repeated at least 40 times throughout the day. They always suffer from pain and discomfort feeling at different body parts and this interferes with their normal work activity to a great extent. Moreover absenteeism means no financial return and even a day's rigourous work fetches meagre income. The inability to support family convincingly even after performing such hazardous tasks makes them feel low. Monotony, boredom, fatigue and mental trauma form an integral part of their daily work schedule.
\end{abstract}

Keywords: physical health, mental health, informal sector

\section{Problem description}

It is a well recognized and acclaimed fact that manual heavy load handling entails enormous physical labor and associated discomfort feeling, which invariably culminate into musculoskeletal disorders (MSD) (Das and Gangopadhyay, 2011). The causation of MSD, in most cases, has been attributed to the adoption of awkward postures while heavy load handling (Splittstoesser et al, 2007 and Gangopadhyay et al, 2003). But what is not identified stringently is the extent to which the workers are mentally exhausted. Mental fatigue, in such instances, becomes an unexplored parameter that needs definite attention during assessment of work status of manual material handling (MMH) workers. Thus mere evaluation of MSD in terms of pain feeling, injuries and accidents will not be able to highlight the miseries of the MMH workers. "Their mental framework, anxiety levels, financial agonies of working in informal sector- all require to be ascertained. The present study is being aimed to evaluate the physical and mental status of porters working in the central market area.

\section{Methodological formulation}

\subsection{Selection of subject}

The study was conducted among 75 randomly selected male workers, having a minimum work

\footnotetext{
Corresponding author e-mail: ganguly1961@yahoo.com
} 
experience of 5 years, engaged in heavy manual load handling in a central market area in Kolkata.

\subsection{Questionnaire study}

SF-12 health status questionnaire was performed among them specifically to analyze the mental status of the MMH workers. The SF-12 is a multipurpose short form survey with 12 questions, weighted and summed to provide easily interpretable scales for physical and mental health. Physical and Mental Health Composite Scores (PCS and MCS) are computed using the scores of 12 questions and range from 0 to 100 , where a zero score indicates the lowest level of health measured by the scales and 100 indicates the highest level of health.

Apart from the above questionnaire, another questionnaire involving psychosocial questions was performed among the same subjects.

\subsection{Assessment of Physical Parameters}

The anthropometric measurements and body weight of the subjects were calculated. The Body Mass Index (BMI), Body Surface Area (BSA) and Waist-Hip Ratio (WHR) were subsequently determined.

\section{Experiment}

The assessment of physical parameters (Table 1) shows that the workers have a mean BMI of 22.1 and waist-hip ratio of 0.89 .

Table 1

Physical Parameters of Workers $(n=75)$

\begin{tabular}{|cc|}
\hline Physical Parameters & Mean $( \pm$ SD) Values \\
\hline Height $(\mathrm{m})$ & $1.63( \pm 6.29)$ \\
\hline Weight $(\mathrm{kg})$ & $59.0( \pm 7.50)$ \\
\hline BMI $\left(\mathrm{kg} . / \mathrm{m}^{2}\right)$ & $22.1( \pm 2.48)$ \\
\hline BSA $\left(\mathrm{m}^{2}\right)$ & $1.64( \pm 0.12)$ \\
\hline Waist Circumference $(\mathrm{m})$ & $0.8( \pm 5.32)$ \\
\hline Hip Circumference $(\mathrm{m})$ & $0.9( \pm 4.42)$ \\
\hline Waist-Hip Ratio & $0.89( \pm 0.11)$ \\
\hline
\end{tabular}

The results of questionnaire analysis have represented an appalling health status of the porters.
Out of the 75 subjects interviewed, the Physical Health Composite Score (PCS) of 68 of them (91\%) is found to be less than 50.0, whereas, the rest is found to have score of greater than 50.0.

Similarly the Mental Health Composite Score (MCS) is also not that satisfying. The MCS of 43 porters is below the score of $50.0(57 \%)$ and the rest has a score in excess of 50.0. The results are an absolute reflection of the alarming situation of the porters in the central market area. In both cases the scores are found to be below average for a significant section of the subjects (Table 2).

Table 2

Analysis of SF-12 Questionnaire $(\mathrm{n}=75)$

\begin{tabular}{|lcc|}
\hline SF-12 Scores & Score $<50.0$ & Score $>50.0$ \\
\hline Physical Health Composite Score & $68(90.7 \%)$ & $7(9.3 \%)$ \\
\hline Mental Health Composite Score & $43(57.3 \%)$ & $32(42.7 \%)$ \\
\hline
\end{tabular}

The assessment of the second questionnaire containing psychosocial questions highly corroborates with the findings of SF 12 questionnaire. Here also about $75 \%$ porters believed that they had no freedom to work according to their will and $80 \%$ felt that they in no way can take decisions on the working procedure. Not only that they have to work very fast, perform strenuous tasks repeatedly throughout the day and have no job security. Amidst all adversities, their only friends are the fellow porters themselves who most often aid in the tasks at times of distress (Table 3).

Furthermore they have to work under such stressful conditions that they suffer constantly from the apprehension of getting seriously injured while at work. According to many of the porters the owner of the market are least bothered regarding their health and safety aspects. 
Table 3

Analysis of Psychosocial Questionnaire $(\mathrm{n}=75)$

\begin{tabular}{|c|c|c|c|c|}
\hline Work Characteristics & Disagree & Agree & Strongly Agree & No Response \\
\hline My job allows me to make a lot of decisions on my own & $40(53.3 \%)$ & $15(20 \%)$ & - & - \\
\hline I have very little freedom to decide how I do my work & $16(21.3 \%)$ & $56(74.7 \%)$ & - & - \\
\hline I get to do a variety of different things on my job & $60(80 \%)$ & - & - & - \\
\hline I have a lot of say about what happens on my job & $60(80 \%)$ & $8(10.7 \%)$ & - & - \\
\hline My job requires working very fast & - & $3(4 \%)$ & $72(96 \%)$ & - \\
\hline My job requires working very hard & $4(5.3 \%)$ & $11(14.7 \%)$ & $60(80 \%)$ & - \\
\hline I have enough time to get the job done & $40(53.3 \%)$ & $8(10.7 \%)$ & $7(9.3 \%)$ & - \\
\hline My job security is good & $10(13.3 \%)$ & $5(6.7 \%)$ & - & - \\
\hline My Sardar (In charge) pays attention to what I am saying & $5(6.7 \%)$ & $52(69.3 \%)$ & $8(10.7 \%)$ & $10(13.3 \%)$ \\
\hline I am exposed to hostility or conflict from my Sardar & $40(53.3 \%)$ & $17(22.7 \%)$ & - & $10(13.3 \%)$ \\
\hline My Sardar is helpful in getting the job done & $5(6.7 \%)$ & $60(80 \%)$ & - & $10(13.3 \%)$ \\
\hline I am exposed to hostility or conflict from the people I work with $20(26.7 \%)$ & $40(53.3 \%)$ & $15(20 \%)$ & - & - \\
\hline People I work with are friendly & - & $31(41.3 \%)$ & $44(58.7 \%)$ & - \\
\hline People I work with are helpful in getting the job done & - & $10(13.3 \%)$ & $65(86.7 \%)$ & - \\
\hline \multicolumn{5}{|l|}{ Work Safety } \\
\hline I am often required to do a task where there is risk of getting hurt - & - & - & $75(100 \%)$ & - \\
\hline There are enough porters here to do the job & $10(13.3 \%)$ & $25(33.3 \%)$ & $40(53.3 \%)$ & - \\
\hline People working here are frequently exposed to dangerous situations - & - & $25(33.3 \%)$ & $50(66.7 \%)$ & - \\
\hline The Owner considers workplace health and safety to be important $28(37.3 \%)$ & $28(37.3 \%)$ & $19(25.4 \%)$ & - & - \\
\hline
\end{tabular}




\section{Critical evaluation and conclusion}

The load handling workers of the central market area, being a part of the informal sector, are deprived of the privileges enjoyed by their counterparts in organized sector. They work throughout the week around 12 hours daily and do not have a specific work schedule. Their rest pauses depend on the workload and availability of manpower. To them absenteeism from work means no financial returns.

On analyzing the physical characteristics of the subjects, it is observed that the mean BMI value of 22.1 falls within the normal range of BMI (Normal BMI: $18-25 \mathrm{~kg} / \mathrm{m}^{2}$ ), as per classification. The mean value of 0.89 of waist-hip ratio suggests that there is

hardly any development of central obesity among the subjects as per classification.

The analysis of SF-12 questionnaire clearly reveals that most of the porters are suffering from some grave physical and mental health problems. The probable causative factors can be summarized as follows. Since most of them are migrant labor, so staying away from family, may lead to feeling of loneliness. Moreover their limited income after a tiring day of work, which at present, is not sufficient to meet the demands of the family, also enhance their anxiety. The inability to support family convincingly even after performing such hazardous tasks makes them feel low and depressed.

Apart from the above findings, whether years of experience had any contribution to the development of physical and mental fatigue was assessed by means of Odds Ratio. The subjects in this study had work experience ranging from more than 10 years up to 30 years. So according to their years of experience, two categories, viz., $>10-20$ years and $>20-30$ years were drawn. The statistical analysis in case of both PCS and MCS revealed that the first category ( $>$ $10-20$ years) was significantly more vulnerable to physical and mental stress (Table 4).

Table 4

Odds Ratio between Years of Experience and PCS and MCS Scores of SF-12

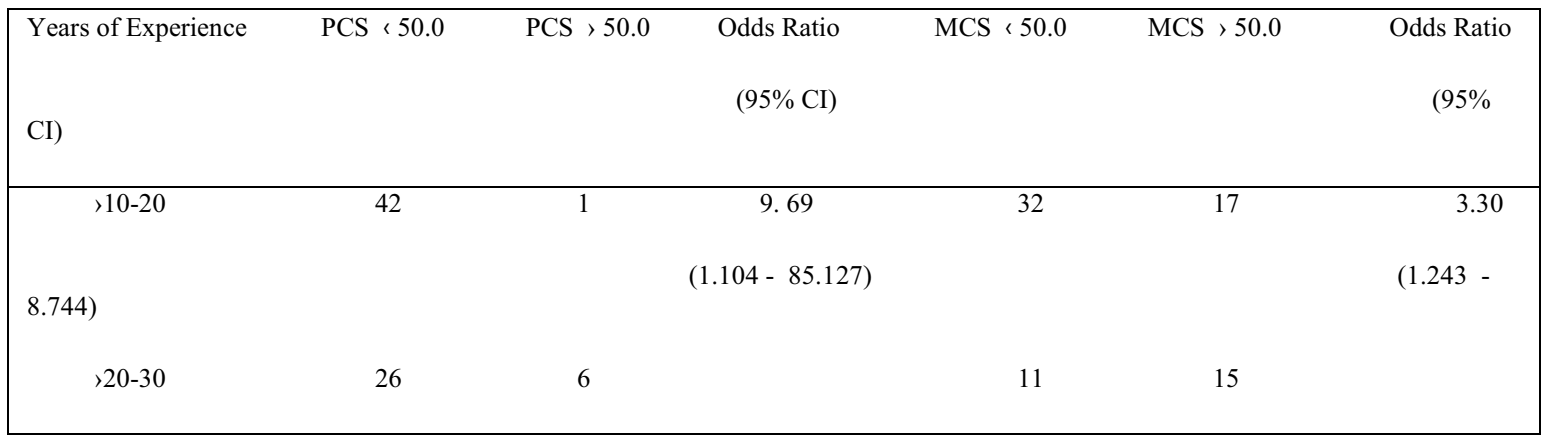

Moreover they are under severe physical exertion as because they alone carry about $120 \mathrm{~kg}$ load maximally and $80 \mathrm{~kg}$ load minimally at a time and such activity are repeated at least 35-40 times

associated with their strenuous tasks are the deplorable environmental conditions with temperature nearing $37.2^{0} \mathrm{C}$ and relative humidity of $87 \%$. The severity of their tasks increases their physical fatigue and discomfort to such an extreme extent that they avoid social outings and gatherings thoughout the day. They always suffer from pain and discomfort feeling at different body parts and this interferes with their normal work activity to a great extent. Substantiating the physical and mental stress after their work. Once they reach their home, they just have meals and go to sleep.

The analysis of psychosocial questionnaire also disclosed a similar finding. It is found that these porters have to work rigorously at a very fast pace to comply the vegetable wholesalers. They rarely get 
any opportunity to exercise their freedom or express their views related to tasks. They completely lack job security as they earn on a daily basis and are not entitled to any leave or additional income benefits. However despite all adversities, they maintain cordial relations with their colleagues and help each other out in times of despair.

The appalling condition of the market contributes considerably towards the generation of mental stress. The fact that the market is too congested with very narrow passageways and debris of rotten vegetables scattered all around, the risk of getting injured or occurrence of injuries while carrying huge loads overhead is premium. Moreover the owner pay no heed towards their welfare and even the expenditure associated with injuries or accidents have to be borne by the porter himself. This continuously creates tremendous mental pressure and they become more cautious during $\mathrm{MMH}$. Not only the uncalled for expenses of accidents and injuries haunt them but also the fear of losing job or absenteeism for prolonged period occupy their mind. Under such circumstances, the worst sufferers will be their family members.

Apart from lack of job autonomy, another factor that plays a significant role in generating mental agony is the practice of performing the same task repeatedly without any variation. Thus it is quite evident that monotony, boredom, fatigue and mental trauma are a part and parcel of their daily work schedule.

\section{Acknowledgement}

The authors express their sincere gratitude to the Indian Council of Medical Research, New Delhi for their financial assistance in the pursuance of this study.

\section{References}

[1] T. Das and S. Gangopadhyay, An ergonomic study on the prevalence of musculoskeletal disorder among the load handling workers of a central market area in Kolkata in: Human Factors in Organizational Design and Management X, Volume II, Chapter 20 Human Factors attributes of industrially developing countries (ISBN 0-9768143-4-X), Matthias Gobel, Candice Christie, Swantje Zschernack, AndrewTodd and Miriam Mattison, ed., IEA press, California, 2011, pp 121-126.

[2] S. Gangopadhyay, T. Das, G. Ghoshal and B. Das, An ergonomic study on the development of musculoskeletal disorders among the fixed load and variable load handling workers of Kolkata, Indian Journal of Biological Sciences 9 (2003), 37-45.

[3] R.E. Splittstoesser, G. Yang, G.G. Knapnik, D.R. Trippany, J.A. Hoyle, P. Lahoti, S.V. Korkmaz, C.M. Sommerich, S.A. Lavender and W.S. Marras, Spinal loading during manual material handling in a kneeling posture, Journal of Electromyography Kinesiology 17 (2007), 25-34. 